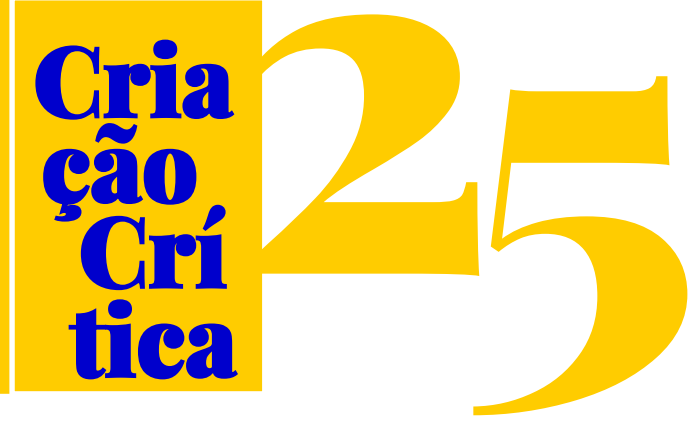

\title{
O DIÁLOGO PRÉ-RAFAELITA DE D’ANNUNZIO E ALMA TADEMA
}

Fabiano Dalla Bona ${ }^{1}$

RESUMO: A interação entre palavras e imagens é perpétua. Algumas vezes a relação é conflitual, outras vezes prevalece um estado de cooperação. Não é insólito que para compensar a ausência de um dos adversários, o outro evoque a sua presença: as imagens ilustram as palavras e as palavras descrevem as imagens. Essa última estratégia é exatamente a ékphrasis, uma das tantas formas nas quais se manifesta a relação entre a literatura e as artes figurativas, especialmente a pintura. É apenas uma palavra, mas seu significado não é unívoco. As discussões sobre o caráter da ékphrasis se entrelaçam com outras disputas sobre as relações entre as duas artes com muita intensidade na obra do italiano Gabriele D'Annunzio. Tratar-se-á das relações e dos diálogos entre os escritos dannunzianos (jornalismo, prosa e poesia) e a obra pictórica do pintor Pré-rafaelita Sir Lawrence Alma Tadema.

PALAVRAS-CHAVE: Gabriele D’Annunzio; Pré-rafaelismo; Alma Tadema; ékphrasis

\section{THE PRERAPHAELIT DIALOGUE BETWEEN D'ANNUNZIO AND ALMA TADEMA}

\begin{abstract}
The interaction between words and images is perpetual. Sometimes the relationship is conflictual, sometimes a state of cooperation prevails. It is not unusual that to compensate the absence of one of the opponents, the other one evokes his presence: images illustrate words and words describe images. This last strategy is precisely ékphrasis, one of the many ways in which the relation between literature and the figurative arts, especially painting, is manifested. It is only a word, but its meaning is not univocal. Discussions on the character of ékphrasis are intertwined with other disputes about the relations between the two arts with great intensity in the work of the Italian Gabriele D'Annunzio. It will deal with the relations and dialogues between Dannunzio's writings (journalism, prose and poetry) and the pictorial work of the PreRaphaelite painter Sir Lawrence Alma Tadema.

KEYWORDS: Gabriele D'Annunzio; Preraphaelism; Alma Tadema ékphrasis
\end{abstract}

\footnotetext{
${ }^{1}$ Doutor em Letras Neolatinas pela UFRJ. Professor Associado de Língua e Literatura Italiana no Departamento de Letras Neolatinas da UFRJ, no Programa de Pós-graduação em Letras Neolatinas (UFRJ) e no Programa de Pósgraduação em Língua, Literatura e Cultura Italianas (USP). Contato: fdbona@gmail.com
} 
Literatura e artes visuais: entre o lisível e o visível

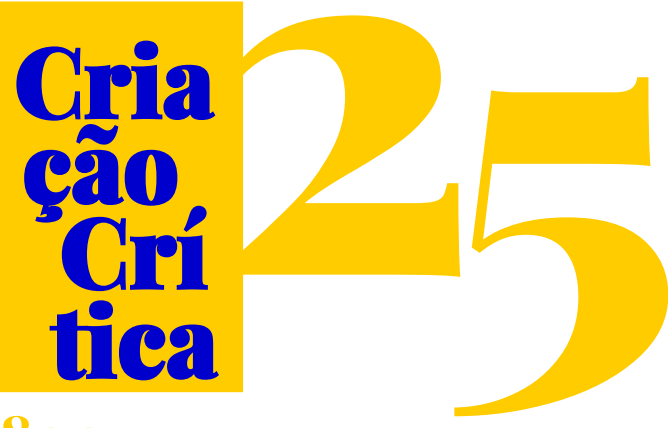

(O) Pré-1rafaelismo na Itália dos anos 1890

Nos anos 1880, a intolerância italiana em relação ao Verismo entra no debate estéticoliterário da península graças às sugestões estrangeiras, em primeiro lugar do Pré-rafaelismo, movimento pictórico-literário fundado em 1848 por Dante Gabriele Rossetti (1828-1882) e cuja difusão em âmbito italiano, e mais especificamente romano, remonta exatamente ao ano de 1881. Naquele ano, Edward Coley Burne-Jones (1833-1898), um dos mais prolíficos artistas do movimento, recebe a encomenda de decorar com mosaicos a Igreja Americana de San Paolo Entro le Mura, a primeira igreja não católica construída em Roma, entre 1873 e 1880.

De filiação romântica, o Pré-rafaelismo ocupa uma posição muito particular no contexto da arte inglesa do século XIX, na qual se encontram algumas das posturas que pré-anunciam a longa estação do decadentismo. A mesma pluralidade de propósitos que agita os pré-rafaelitas, frequentemente em aparente contradição entre si, denota a abertura em relação a interesses culturais compósitos, bem como a sugestiva retomada do passado - a Idade Média como ideal de vida harmoniosa e a arte italiana que precede Rafael Sanzio (1483-1520) como modelo de pureza da linguagem visual - é continuamente colocada em confronto, algumas vezes de modo confuso, outras com uma resolução deliberada, particularmente com as realidades culturais coevas e com o pensamento de John Ruskin (1819-1900).

Quando em 1848, o poeta e pintor Dante Gabriele Rossetti funda a Preraphaelite Brotherhood (Fraternidade Pré-rafaelita), imediatamente recebe a adesão de Willam Holman Hunt (1827-1910), John Everett Millais (1829-1896) e Ford Madox Brown (1821-1893). Como já havia ocorrido com os Nazarenos alemães do início do século², uma vocação mística congrega os jovens artistas e, com ela, a convicção que a ação do artista é uma forma de missionarismo. Eles acreditam ser investidos pelo ato de, através da arte, elevar as condições de vida das massas trabalhadoras que a expansão da indústria havia brutalizado, apagando nelas qualquer possível espiritualidade. Daqui essa ligação ideal com a Idade Média, mas daqui também o aceite das propostas socialistas.

Entre classe política, sistema feudal, aristocracia conservadora, burguesia liberal e movimento operário, se instala um clima de forte conflito. O bem-estar material, no fim das contas, estava sendo eleito como meta e modelo de vida de uma sociedade industrializada. Nesse clima ideal de utilitarismo carregado de contradições, de convicções desiludidas e de passionalidade mortificada é que a inspiração medieval e nostálgica do passado toma forma. A difusão de tal concepção cultural se dá graças à produção literária e crítica de Ruskin, fervoroso opositor da civilização mecanizada, e que com sua postura reacionária prepara o terreno para o Pré-rafaelismo. Mas o empenho humanitário, o espírito evangélico e um certo realismo, presentes no programa inicial da Irmandade Pré-rafaelita, e que haviam determinado o apoio de Ruskin e o interesse de William Morris (18341886) ao grupo, desaparecem. Rossetti passa a ser reconhecido como expoente do grupo e, não por acaso, torna-se o artista mais apreciado na Itália, pois sustentava a ideia da beleza autossuficiente e

\footnotetext{
${ }^{2}$ Grupo de artistas liderados por Johann Friedrich Overbeck (1789-1869) e Franz Pforr (1788-1812) que em 1809 fundaram em Viena a Irmandade de São Lucas (Lukasbund), efetivamente o primeiro movimento pictórico europeu em polêmica direta com a Academia e a corrente neoclássica do século XVIII. Em 1810 se transferiram para Roma e ali congregaram outros artistas como Peter Cornelius (1783-1867), Johann Konrad Hottginger (1788-1827), Josef Sutter (17811866) e outros, e se inspiravam na obra de Albrecht Dürer (1471-1528) e dos pintores italianos do século XV, principalmente Perugino (1466-1523), Luca Signorelli (1450-1523) e Rafael Sanzio (1483-1520); tratavam de temas bíblicos e da vida dos santos (TAVOLA, 2010).
} 


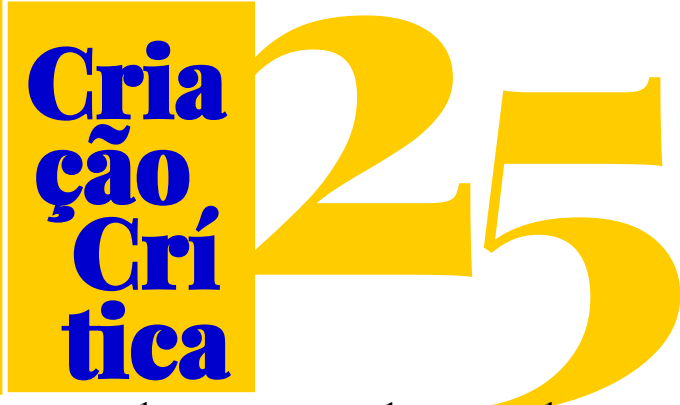

da arte pela arte. O Primitivismo ${ }^{3}$, que caracteriza o movimento na Inglaterra, em ambiente italiano torna-se, principalmente, uma ocasião para redescobrir a pintura nacional e um forte apelo ao classicismo e ao Renascimento.

Para além do aspecto cultural, a exigência de fugir da atmosfera cinzenta da sociedade industrial não estava sendo sentida na Itália dos anos 1860 e 1870, pois há pouco tempo ela existia como nação; contrariamente àquilo que ocorria na Inglaterra e na França, a economia italiana era praticamente agrícola, e a literatura e a arte estavam ainda fortemente marcadas pelo academicismo e pela tradição. Os intelectuais da península italiana estavam empenhados em refletir sobre problemas de sua própria cultura como a questão linguística (italiano língua oficial versus dialetos) e também com a criação de uma literatura realmente nacional.

É, portanto, na década de 1880 que "a afetação de vestes extravagantes, de flores excepcionais e de poses decadentes - efeito da propaganda pré-rafaelita, e especialmente da poesia de Swinburne, da escola decorativa de Morris, e dos livros de W. Pater (1873) e de J. A. Symonds (1875) sobre o renascimento italiano" (PRAZ, 2005, p. 130) dominam a Itália. Especialmente na Roma fin de siècle, na chamada Roma bizantina, "prevalecem posturas exteriores, retraduções apressadas ou, se assim se quer, um mais genérico milieux anglais à la mode que, em si, conforma sob a dúctil etiqueta de gosto" (D'ANNA, 1996, p. 323)5; se na Itália o esteticismo era superficial e decorativo, na Inglaterra, ao invés, representava realmente uma corrente que criava um novo imaginário e ditava um novo estilo de vida e de moda.

Em 1886, Giovanni Costa (1826-1923)

\begin{abstract}
[...] organizou em Roma uma exposição no studio Giorgi na Via S. Nicolò Tolentino, apresentando todas aquelas forças, velhas e novas, unidas pelos mesmos interesses de renovação, agora e sempre mais próximas às contemporâneas correntes literárias e figurativas do esteticismo. O grupo, que compreendia O. Carlandi, V. Cabianca, A. Morani, A. Ricci, os outros "etruscos" dentre os quais G. Cellini, por este foi chamado "In Arte Libertas". Foram organizadas mostras anuais até 1902, apresentando artistas italianos junto com artistas estrangeiros, principalmente ingleses e franceses. (PIANTONI, 1984, p. $38)^{6}$
\end{abstract}

O citado In Arte Libertas era "um movimento que no rastro das teorias de John Ruskin e William Morris propunha uma pesquisa artística livre de vínculos acadêmicos" (SPEZIALI, 2017, p.

\footnotetext{
${ }^{3}$ Primitivos são aqueles pintores que segundo Giorgio Vasari (1511-1574) precederam Michelangelo (1475-1564), Rafael Sanzio e os grandes mestres que o historiador, arquiteto e pintor florentino considerava como mestres insuperáveis em sua Vite dei piu Eccellenti Pittori, Scultori ed Architetti Italiani (Vida dos mais Importantes Pintores, escultores e Arquitetos Italianos), publicada em 1550.

4 "l'affettazione di vesti stravaganti, di flori eccezionali, e di pose decadenti - effetto della propaganda preraffaellita, e specialmente della poesia di Swinburne, della scuola decorativa del Morris, e dei libri di W. Pater (1873) e di J. A. Symonds (1875) sul Rinascimento italiano." (Todas as traduções, quando não indicado explicitamente nas Referências, são do autor.)

5 "prevalgono atteggiamenti esteriori, ritraduzioni frettolose o, se si vuole, un più generico milieux anglais à la mode che tutto in sé conforma sotto la duttile etichetta del gusto"

6 "[...] organizzò a Roma una esposizione nello studio Giorgi in via S. Nicolò da Tolentino, presentando tutte quelle forze, vecchie e nuove, unite negli stessi intenti di rinnovamento, ora e sempre più vicine alle contemporanee correnti letterarie e figurative dell'estetismo. Il gruppo, che comprendeva O. Carlandi, V. Cabianca, A. Morani, A. Ricci, gli altri "etruschi" fra i quali G. Cellini, fu da questo chiamato "In Arte Libertas". Si organizzarono mostre annuali fino al 1902, presentando artisti italiani insieme con artisti stranieri, in particolare inglesi e francesi."
} 


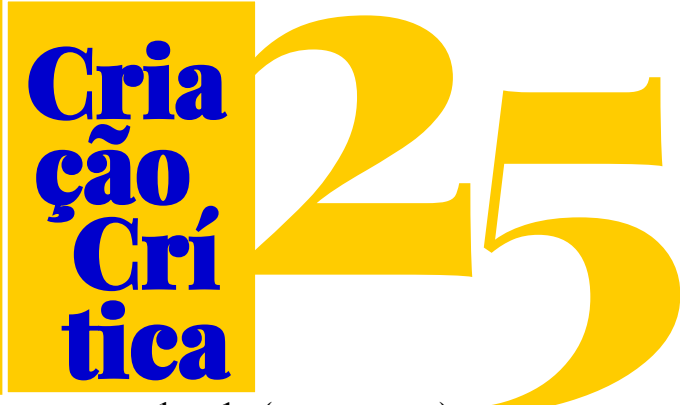

359). Dela faziam parte Vincenzo Cabianca (1827-1902), Onorato Carlandi (1848-1939), Giuseppe Cellini (1855-1940), Enrico Coleman (1846-1911), Adolfo De Carolis (1874-1928), Mario De Maria (1852-1924), Alessandro Morani (1859-1941), Alfredo Ricci (1864-1889) e Giulio Aristide Sartorio (1860-1932). A sociedade, conotada por características secessionistas de tipo antiacadêmico, em polêmica com a arte oficial, constitui o trâmite decisivo para a difusão do gosto pré-rafaelita na Itália. Na primeira mostra, que ocorreu no atelier Giorgi, em Roma, foram expostas obras de artistas italianos e dos estrangeiros Rossetti, Burne-Jones e de Arnold Böcklin (1827-1901).

Contemporaneamente, o filósofo e crítico de arte Angelo Conti (1860-1930) tornou-se o guia espiritual de pintores e escritores que se inspiravam nos ingleses e que se propunham a realizar um fronte unitário de literatos e pintores, dentre os quais encontrava-se o jovem Gabriele D'Annunzio, recém-chegado à capital. Na opinião de Ricorda, a produção de Conti é constituída "[...] pelas profundas ligações com a cultura inglesa, particularmente com intelectuais do movimento prérafaelita como William Morris, e, principalmente com o próprio Ruskin, por ele conhecido pessoalmente e admirado como sumo mestre" (1995, p. 420). ${ }^{7}$ Conti era um verdadeiro mediador cultural da sensibilidade pré-rafaelita lida através dos olhos de Ruskin. ${ }^{8}$

\section{O encontro de D’Annunzio com a obra de Alma Tadema}

Gabriele D’Annunzio (1863-1938) entra em contato com o Pré-rafaelismo progressivamente. Em 1880 escreve uma carta ao escritor e crítico literário Giuseppe Chiarini (1833-1908), diretor do suplemento literário Domenica del Fracassa, um dos anglófilos italianos com os quais ele mantinha contatos desde o seu tempo de estudante no Real Colleggio Ciccognini de Prato. A carta mostra o jovem intento a fazer traduções não apenas do grego e do latim, como era óbvio, mas também do inglês: "Agora dou ouvidos aos teus conselhos: traduzo do latim e do grego; tentei também uma poesia delicadíssima de Tennynon, mas com pouco sucesso. [...] O Tennysson me parece ser um dos poetas mais difíceis de ser traduzido, especialmente nas poesias líricas" (HERMOSILLA, 1995, p. 234) ${ }^{9}$. Tal carta manifesta um interesse bastante precoce pela poesia pré-rafaelita e um conhecimento, mesmo que elementar, da língua inglesa.

Três anos depois, em carta ao mestre, poeta, crítico literário e tradutor Enrico Nencioni (1837-1896), de 30 de dezembro de 1883, mais uma vez emerge o seu interesse por Alfred Tennyson (1809-1892): "Para o último número [da Cronaca Bizantina] traduzi algumas estrofes deliciosas do Tennyson, The sleeping beauty do Day-dream." (FORCELLA, 1939, p. 9) ${ }^{10}$ A escolha dessa poesia é expressiva, pois era uma das preferidas dos pré-rafaelitas ingleses e havia inspirado numerosas versões da lenda medieval, dentre as quais uma pintada por Burne-Jones. Todavia, o aspecto mais

\footnotetext{
7 "[...] dai profondi legami con la cultura inglese, in particolare con intellettuali del movimento preraffaellita come William Morris, e soprattutto con lo stesso Ruskin, da lui conosciuto personalmente e ammirato come sommo maestro." ${ }^{8}$ O figuralismo é o terreno de encontro entre Ruskin e os pré-rafaelitas. Desde 1852 o sempre crescente interesse dele pelos problemas políticos e sociais caracteriza a sua produção não apenas de pintor, mas de teórico, com a publicação de The Political Economy of Art (Economia politica da arte) em 1857, além de Modern Painters (Pintores Modernos) em cinco volumes, estudos sobre Botticelli (1872-1873), além da catalogação de obra de Turner e manuais técnicos sobre desenho e pintura.

9 "Ora do retta ai tuoi consigli: traduco dal latino e dal greco; ho tentato anche la poesia delicatissima del Tennyson, ma con poco frutto. [...] Mi pare che il Tennyson sia uno dei poeti più difficili a tradursi, specialmente nelle liriche."

10 "Per l'ultimo numero [della Cronaca Bizantina] ho tradotte delle strofe squisite del Tennyson, The sleeping beauty del Daydream."
} 
significativo que se pode deduzir dessa missiva é o interesse de D'Annunzio pela poesia inglesa e que o impulsiona ao conhecimento dos pintores pré-rafaelitas.

Outro elemento que assinala o ano de 1883 como crucial para o crescente interesse de D'Annunzio pela cultura inglesa é o primeiro verdadeiro contato dele com um pintor inglês, por ocasião da Esposizione Nazionale di Roma (Exposição Nacional de Roma). Em sua dupla veste de poeta e arbiter elegantiarum, escritor e cantor da Roma Capital, torna-se

[...] mestre de crônicas mundanas descrevendo com igual elegância as exposições de arte e os vestidos das damas, modas orientalizantes e novos gostos de AlémAlpes, mexericos e atualizações culturais. Entre as páginas frívolas, assinadas com pseudônimos (Il Duca Minimo, Lila Bisquit, Vere de Vere, Bull-Calf) despontam Baudelaire e Mallarmé, Flaubert e Zola, Keats e Swinburne, prérafaelitas e parnasianos: a nova cultura da Europa. (GIBELLINI, 1995, p. XXIX) ${ }^{11}$

Em seus artigos para o Fanfulla e o Fanfulla della Domenica, D'Annunzio celebra as obras de Lawrence Alma Tadema (1836-1912). Com o pseudônimo de Bull-Calf na crônica "Arte e ArtistiInseguimento" (Arte e Artistas - Perseguição), na edição do Fanfulla de 22 de janeiro de 1883, lemos:

Eu a vi pela primeira vez lá, diante dos três quadros de Alma-Tadema, e tinha a cabeça um pouco curvada e os grandes olhos abertos cheios de maravilha e de verde-mar. Talvez a fina miniatura e aqueles tons frios de pedra e de metal, e aqueles tipos de mulheres sombreadas na doce serenidade da beleza e aquele hálito de vida antiga circulante entre os mármores e aquele não sei o quê de compostamente jucundo fascinavam-na. Ela curvara-se ainda mais sobre o Atelier de sculpture, sorrindo àquela divina figura mulíebre alta e branca de cabelos vermelhos. Depois saiu da sala, ainda virando-se para trás, para sorrir na direção a Tadema. (D’ANNUNZIO, 1996, p. 13)

Embora o autor fale de uma bela mulher que persegue pelas salas da mostra, é exatamente em frente ao quadro de Tadema que ele admira a mulher perseguida e estabelece uma analogia entre a figura que observa o quadro e aquela que é observada no quadro. As obras de Tadema expostas na mostra romana realmente impactaram o jovem D'Annunzio, e eram elas: The question (A pergunta), $A$ picture gallery (Uma galeria de pinturas), A sculpture gallery (Uma galeria de esculturas), The vintage festival (A festa da vindima) e A staircase (Uma escadaria), respectivamente com os números 184 (p. 23) 15 e 16 (p. 85) e 185 (p. 23)

No centro da cena que a mulher perseguida observa há uma figura feminina. Mas na maioria das obras de Tadema há sempre uma figura feminina que domina a cena: musa ou modelo, femme

\footnotetext{
${ }^{11}$ [...] maestro di cronache mondane descrivendo con pari eleganza esposizioni d'arte e abiti di dame, mode orientaggianti e nuovi gusti d'oltralpe, pettegolezzi e aggiornamento culturale. Fra le pagine frivole, firmate con pseudonimi (Il Duca Minimo, Lila Bisquit, Vere de Vere, Bull-Calf) fanno però capolino Baudelaire e Mallarmé, Flaubert e Zola Keats e Swinburne, preraffaelliti e parnassiani: la nuova cultura d'Europa.

12 "L'ho veduta la prima volta là, dinanzi ai tre quadri di Alma-Tadema, che aveva la testa un po' china e aperti i grandi occhi pieni di meraviglia e di verdemare. Forse la miniatura fine e quei toni freddi di pietra e di metallo, e quei tipi di donne ombrati nella dolce serenità della bellezza, e quell'alito di vita antica circolante fra i marmi e quel non so che di compostamente giocondo l'affascinava. Ella s'è chinata ancora più su l'Atelier de sculpture, sorridendo a quella divina figura muliebre alta e bianca, dai capelli rossi. Poi è uscita dalla sala, volgendosi indietro ancora, a sorridere verso Tadema."
} 
fatale ou heroína, maga ou princesa, a figura de mulher de traços angelicais ou demoníacos é o seu tema predileto.

Sempre nas páginas do Fanfulla, Bull-Calf, em 8 de março de 1883, em "Arte e ArtistiAcquarelli e Pastelli" (Arte e Artistas - Aquarelas e Pastéis), indica que a sala das aquarelas da Exposição é pouco visitada e que os espectadores apenas passam os olhos por elas, mas o jornalista anota: "Algum poeta ocioso permanece longamente a sonhar defronte ao idílio antigo de Alma Tadema, fascinado pelos divinos olhos azulados da jovem dubitante. Depois, aos intervalos, solidão gélida" (D'ANNUNZIO, 1996, p. 47) ${ }^{13}$. A referência é à obra The Question, e a referência ao poeta ocioso é o próprio D'Annunzio que fica fascinado com a aquarela. Após a descrição de aquarelas de artistas italianos, assim encerra o texto: "Mas eis Alma Tadema. A lírica possui outro tempo" (D'ANNUNZIO, 1996, p. 50) ${ }^{14}$.

Reiterando, são as belezas mulíebres - termo caro ao escritor - do pintor anglo-holandês que afetaram o imaginário dannunziano e que irão merecer sua atenção ao publicar, dessa vez com seu próprio nome e não com pseudônimo, a crônica "Esposizioni d'arte IV - ALMA TADEMA" (Exposições de Arte IV - ALMA TADEMA), no Fanfulla della Domenica de 1 de abril de 1883. Trata-se do primeiro ensaio crítico sobre o pintor publicado na Itália:

É uma pintura gemante, algo como uma peça rara de prataria antiga, algo como uma joia carregada de cinzeladuras, um marfim esculpido e gravado, um alabastro milagrosamente perfurado: assim. Fica-se ali a olhar, a observar, a buscar com uma curiosidade de antiquário que tem a paixão dos cimélios, das miniaturas sobre pergaminho, das folhagens esguias ao redor dos capitéis, dos fragmentos de baixos-relevos floridos, de camafeus antigos; assim. Efeito singular: olhando, observando, buscando, primeiramente não se pensa em obra do pincel sapiente e paciente. Aquelas telas parecem ter uma rigidez quase hialina, quase que uma consciência de pedra dura; certas peças parecem de marchetaria, certas outras de mosaico florentino, certas outras de esmalte, aqui e ali a cor adquire como que uma transparência ambarizada, aquela espécie de tom áureo difuso do qual o tempo enriquece os retratos venezianos. Sente-se que muitos efeitos de superfície e de qualidade são obtidos com procedimentos técnicos seríssimos, com preparações de tintas sobrepostas, em sua maioria. O pincel não se vê jamais, jamais se vê o toque; a diversidade de matéria nos objetos que preenchem aqueles interiores não é obtida com a diversidade da pincelada, com os impastos, com os espatulados, com os martelamentos, com o pontilhismo, enfim, com todos aqueles pequenos meios dos quais, hoje, muitos pintores se servem. (D'ANNUNZIO, 1996, p. 131)

\footnotetext{
13 "Qualche poeta ozioso sta longamente a sognare dinanzi all'idillio antico di Alma Tadema, ammaliato dai divini occhi azzurognoli della fanciulla dubitante. Poi, a intervalli, solitudine gelida."

14 "Ma ecco Alma Tadema. La lirica ha un'altra volta."

15 "È una pittura gemmea, qualche cosa come un pezzo raro di argenteria antica, qualche cosa come un gioiello carico di cesellature, un avorio scolpito e inciso, un alabastro miracolosamente traforato: cosi. Si resta li a guardare, ad osservare, a ricercare con una curiosità di antiquario che abbia la passione dei cimelii, delle miniature su la pergamena, dei fogliami esili intorno ai capitelli, dei frammenti di bassorilievi fioriti, dei cammei antichi; cosi. Effetto singolare: guardando, osservando, ricercando, da prima non si pensa ad opera di pennello sapiente e paziente. Quelle tele paiono avere una rigidezza quasi jalina, una coscienza quasi di pietra dura; certi pezzi paiono ad intersio, certi altri a musaico fiorentino, certi altri a smalto. Il colore qua e là prende come una trasparenza ambrata, quella specie di tono aureo diffuso di cui il tempo arrichisce i ritratti veneziani. Si sente che molti effetti di superficie e di qualità sono ottenuti con procedimenti
} 


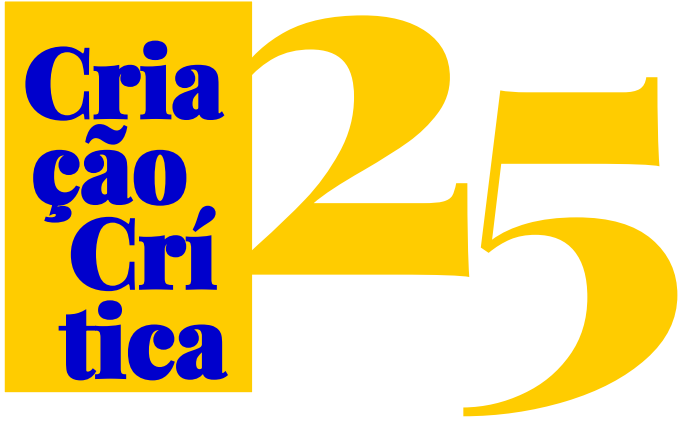

Nessa primeira parte, D'Annunzio exalta as qualidades técnicas do artista e descreve a obra utilizando-se de comparações por símile. Em seguida, se debruça sobre o tipo feminino proposto pelo pintor:

Todavia, aquelas figuras atraem: são tipos finíssimos, possuem algo de nobre na postura e na expressão, pouquíssimo caráter de romanidade. O tipo mulíebre de Alma Tadema é de cabeleira de um vermelho ardente de ouro, diáfano no rosto, cheio de graça tranquila. Tal tipo ideal de beleza antiga, sonhado por um flamengo nas primaveras vaporosas da Inglaterra, aparece quase sempre em uma túnica rósea e branca; possui uma castidade de virgem nórdica; possui as íris de turquesa serena, às vezes atônitas. (D'ANNUNZIO, 1996, p. 131)

A obra de Tadema homenageia o mundo clássico, ele que foi um dos mais ardentes propagadores da art pour l'art. São produções que narram uma vida devotada a estudar, a reproduzir e a colecionar antiguidades com a finalidade de recompor a eclética variedade de um mundo desaparecido. São esculturas, fragmentos arquitetônicos, objetos, adereços e utensílios, assemblados segundo livres associações e manipulados à moda do pintor e gravador maneirista Giovanni Battista Piranesi (1720-1778); os objetos quase roubam a atenção à presença humana. Mas principalmente as mulheres, de absoluta e intangível beleza, dedicadas às atividades contemplativas ou ao culto de divindades pagãs são as verdadeiras protagonistas. Ao invés de servirem de fundo aos retratos de soberanos ou às gestas dos heróis, os achados arqueológicos estão imersos em uma dimensão cotidiana, todavia interpretada em chave estetizante e, por isso, suspensa entre a realidade e o mito. Ou nas palavras de D'Annunzio:

Mas as diferenças materiais resultam, não obstante com evidência, admiráveis, resultam por composição de cores: os metais são metais, os mármores são mármores, as madeiras são madeiras. Todas aquelas finas florescências arquitetônicas e aquelas alfaias sacras e aqueles ornamentos elegantes; todos aqueles fundos agradavelmente harmônicos de paredes em relevo e de colunas em fuga são estudados e executados com uma harmoniosidade pesquisadora, com uma minuciosidade incansável, com um cuidado igual. Parece que o artista prefira todas aquelas coisas mortas; toda aquela inanimada compostura de estátuas parece que tenha um encanto para ele. A marmoreidade, por assim dizer, também enrijece as figuras humanas que se erguem naquela luz. As carnes adquirem uma nitidez cristalina, as vestes não possuem a fluidez de pregas, não possuem maciez. (D'ANNUNZIO, 1996, p. 131) ${ }^{17}$

tecnici seriissimi, con preparazioni di tinte sovrapposte per lo più. Il pennello non si vede mai, non si vede mai il tocco; la diversità di materia nelli oggetti che empiono quelli interni non è resa con la diversità della pennellata, con le grossezze, con le grattature, con i martellamenti, con i pichiettamenti, con tutti insomma quei piccoli mezzi di cui molti pittori oggi si servono."

16 "Pure, quelle figure attraggono: sono tipi finissimi, hanno tutti qualcosa di signorile nell'atteggiamento e nell'espressione, pochissimo carattere di romanità. Il tipo muliebre amato de Alma Tadema è di chiome d'un rosso ardente di oro, diafano nel viso, pieno di grazia tranquilla. Codesto ideale di bellezza antica, sognato da un fiammingo nelle primavere vaporose d'Inghilterra, appare quasi sempre in una tunica rosea o bianca; ha una castità di vergine nordica; ha le iridi di turchesia serena talvolta attonite."

17 "Ma le differenze materiali risultano nondimeno con evidenza mirabili, risultano per composizione di colore: i metalli sono metalli, i marmi sono marmi, i legni sono legni. Tutte quelle fini fioriture architettoniche e quelle suppellettili sacre 
Literatura e artes visuais: entre o lisível e o visível

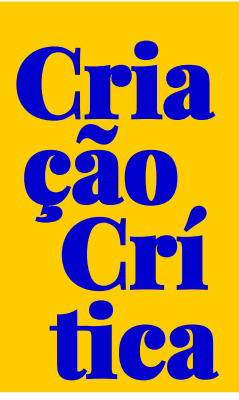

contemplação da obra de arte anima o seu rosto. Ela observa, com a mão apoiada sobre a cabeça morena de um menino. (D'ANNUNZIO, 1996, p. 131) ${ }^{19}$

Tal tipo de beleza aparece, naquele mesmo ano, em "Peccato di maggio" na coletânea Intermezzo di Rime:

Ora foi assim; íamos pelo bosque. Sutil

ela era e toda loura; sobre a nuca infantil

dois cachos tinham aquele quentes brilhos vermelhos

que possuem as virgens antigas de Tadema; entre os cílios

longos os olhos tinham a íris esverdeada, radiante

de finos ácinos d'ouro. Da alta relva odorante

ela surgia ereta, como um fuste vivente.

Nós íamos pelo bosque. Sobre um fundo de céu

alaranjado as grandes árvores, em frente, nas folhagens

assumiam tintas metálicas, tons intensos de cobre

pareciam fundidos no bronze os troncos, mas debaixo

das cascas, passando, sentíamos interrupto

em nós ascender o arrepio pugnante das linfas

e o romper das gemas nós sentíamos. (D’ANNUNZIO, 1884, p. 25) ${ }^{20}$

É possível observar uma escolha lexical coincidente entre a crônica jornalística e a poesia. Comparada a uma maga, a mulher possui um encantador fascínio, principalmente os cabelos vermelhos. Nos citados versos estão alguns leitmotive da caracterização pré-rafaelita de D'Annunzio: a figura esguia, as cabeleiras louras e ruivas, os conotados cromáticos como o verde e o ouro e o aspecto metálicos das cores e dos elementos naturais. São atributos distintivos das beldades da aristocracia romana que povoam as crônicas mundanas do Vate, especialmente a figura de Miss Multon "a deidade de Alma Tadema, com o rosto puro de linhas e alabastrino de cor, coroada por uma ascensão de cachos vermelhos" (D'ANNUNZIO, 1996, p. 231) 21, a "moça dos cachos flamejantes como aqueles da Aurora, saltada para fora daquele quadro da Festa de Baco" (D'ANNUNZIO, 1996, p. 1046) ${ }^{22}$. A partir de 1885, Miss Multon é sempre associada ao "doce pintor louro" (D'ANNUNZIO, 1890 , p. 1890) ${ }^{23}$. Il Marchese di Caulonia, outro dos pseudônimos dannunzianos, em 27 de janeiro de

\footnotetext{
19 "Ma la figura di dea, che io vorrei avere dinanzi a me dipinta su una striscia di avorio, la figura ideale è nell'Atelier de sculpture, alta diritta, tutta in una veste rosea che fa pensare alla nudità. Pare balzata fuori da un meraviglioso pezzo di alabastro; è fulgente. La testa pura dalla pura bocca, dai puri occhi, si leva come in una specie di nimbo fiammeggiante, nel nimbo dei capelli rossi che coprono per due grandi ciocche la nuca. Il godimento sereno della contemplazione dell'opera d'arte le anima la faccia. Ella guarda, poggiata la mano su 'l capo bruno di un fanciullo."

${ }^{20}$ Or cosi fu; pe 'l bosco andavamo. Sottile/ ella era e tutta bionda; su la nuca infantile/ due ciocche avean que' caldi luccicori vermigli/ che han le vergini antiche di Tadema; tra i cigli/ lunghi li occhi avean l'iride verdognola, raggiante/ di fini àcini d'oro. Da l'alta erba odorante/ ella sorgeva eretta, come un vivente stelo./ Noi andavam pe 'l bosco. Sopra un fondo di cielo/ aranciato i grandi alberi, dinanzi, ne 'l fogliame/ prendean tinte metalliche, toni intensi di rame;/ parean fusi ne 1 bronzo i tronchi, ma di sotto/ a le scorze, passando, sentivamo interrotto/ noi ascendere il brivido pugnante de le linfe/ e il romper de le gemme noi sentivamo.

21 "la deità di Alma Tadema, con il volto puro di linee ed alabastrino di colore, incoronata da un'accensione di chiome rosse".

22 "fanciulla dalle chiome fiammeggianti come quelle dell'Aurora, balzata fuori da quel quadro della Festa di Bacco"

23 "dolce pittor biondo"
} 


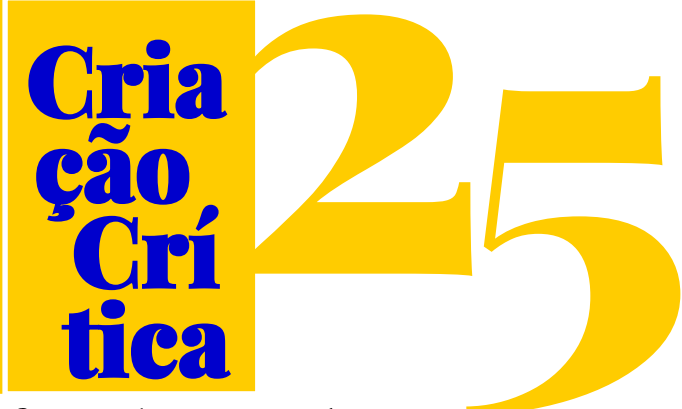

1886 na crônica "Balli e serate" (Bailes e noitadas) resume a figura de Miss Multon nos seguintes termos: "[...] será a belíssima, terá uma cabeça que Alma Tadema poderá pintar 'sobre um fundo de loendros'; terá sobre a cabeça uma 'ascensão de cachos vermelhos'; os seus ombros perfeitos serão de puro marfim. Ela terá um pré-rafaelítico vestido de tecido amarelo ou verde-mar" (D'ANNUNZIO, 1996, p. 505, grifos nossos) ${ }^{24}$. O mesmo motivo retorna no primeiro romance dannunziano, Il piacere, publicado em 1889: "Uma dançarina que tinha sobre a testa branca como o mármore de Luni, uma ascensão de cachos vermelhos, à semelhança de uma sacerdotisa de Alma Tadema" (D'ANNUNZIO, 2009 , p. 97 $)^{25}$

Em "L'Adorazione" (A Adoração) do grupo dos "Sonetti d'Ebe" (Sonetos de Hebe) presentes na coletânea Isaotta Guttadauro (1886), mais uma vez ele cita o pintor:

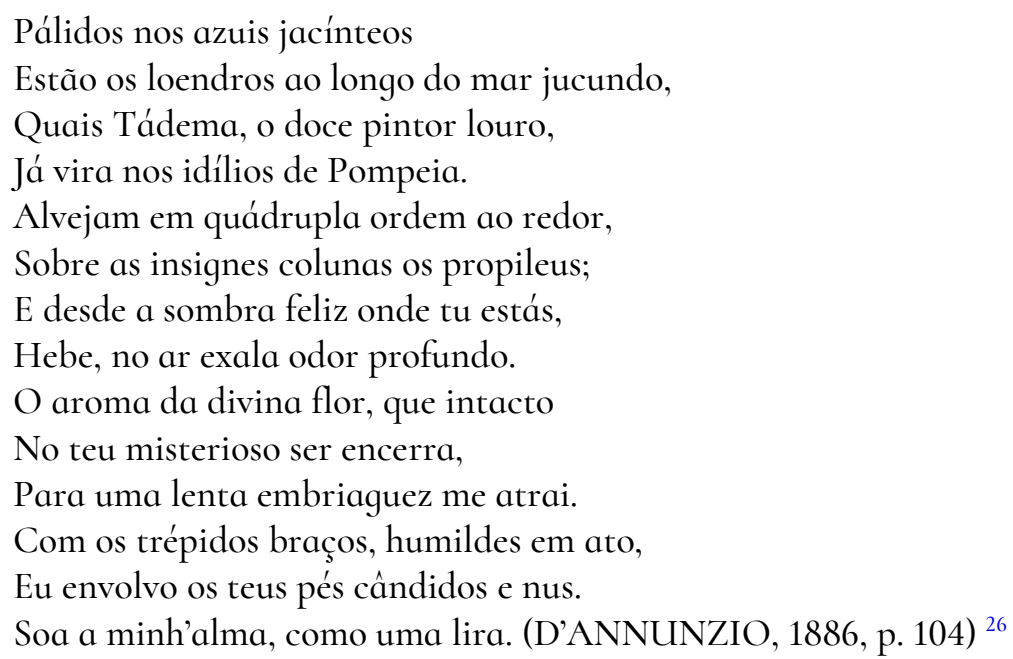

O léxico que D'Annunzio utiliza para descrever as mulheres tademescas, com especial atenção ao campo semântico do cromatismo, são constantemente reutilizados para descrever as mulheres romanas em suas crônicas mundanas. Mas ele não se limita ao cromatismo: as mulheres são retratadas com um acento sensual e com um ar de abandono, um resumo das características das mulheres pré-rafaelitas.

\footnotetext{
24 "[...] sarà la bellissima, avrà una testa che Alma Tadema potrà dipingere "su un fondo di oleandri"; avrà su la testa "un'accensione di chiome rosse"; le sue spalle perfette saranno di puro avorio. Ella avrà un preraffaellitisco abito di velo giallo o di velo verdemare."

25 "Una danzatrice che aveva in su la fronte bianca come il marmo di Luni un'accensione di chiome rosse, a similitudine d'una sacerdotessa d'Alma Tadema."

26 "Pallidi ne li azzurri jacintèi/ stan li oleandri lungo il mar giocondo, /quali Tádema, il pittor biondo, /già vide ne li idilli di Pompei./ Biancheggiano in quadruplo ordine a tondo/ su le insigni colonne i propilei; / e da l'ombra felice ove tu sei,/ Ebe, ne l'aria sale odor profondo./ L'aroma de 'l divin fiore, che intatto/ ne 'l tuo misterioso essere chiudi, / per una lenta ebrïetà m'attira / De le trepide braccia, umile in atto, / io ricingo i tuoi piè candidi e nudi./Suona l'anima mia, come una lira."
} 
Literatura e artes visuais: entre o lisível e o visivel
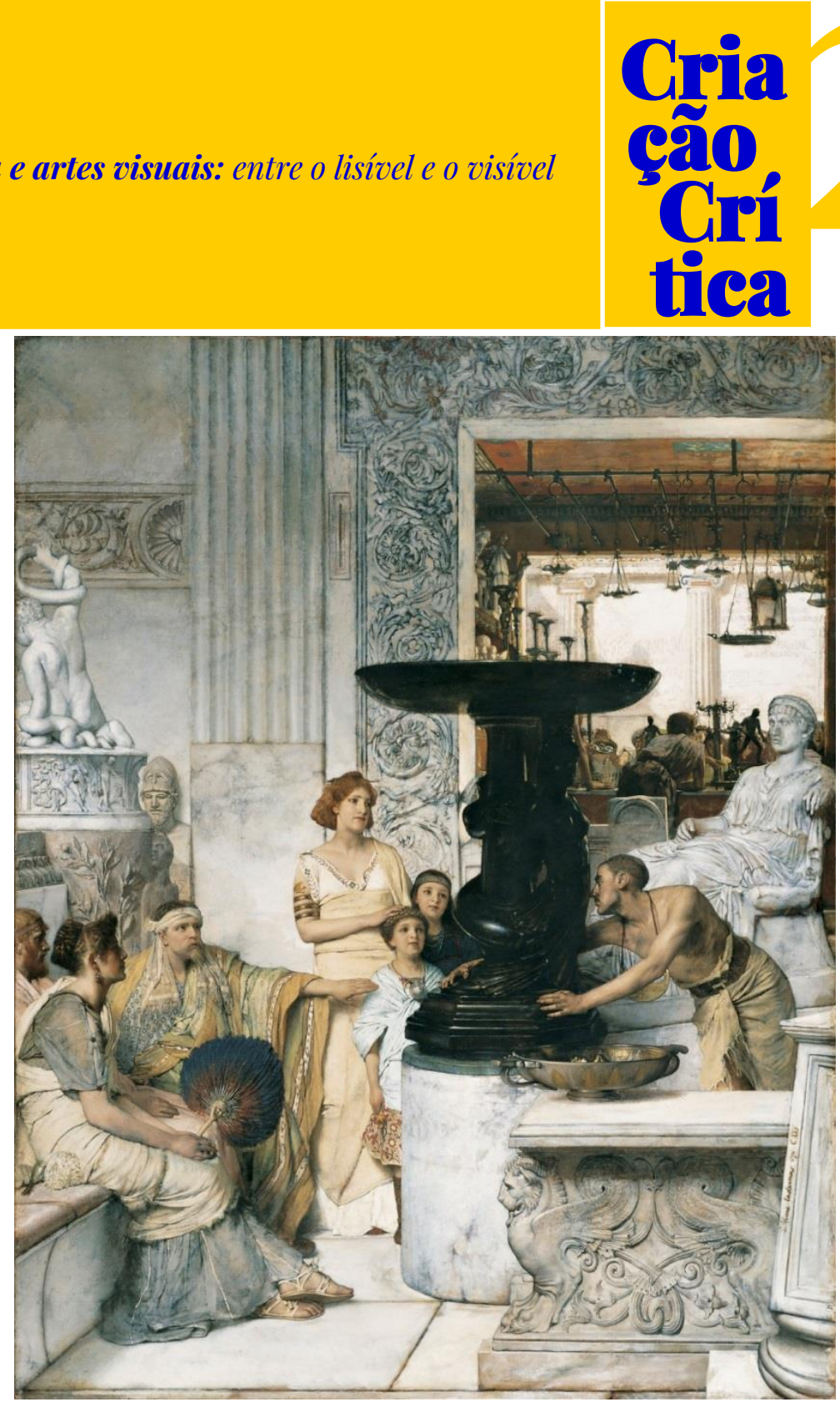

Figura 1: The sculpture gallery - o.s.t, 219,7 X 171,5 cm, 1875.

D'Annunzio prossegue utilizando uma ékphrasis ${ }^{27}$ :

Em frente a ela, sobre a base, o escravo gira um grande vaso de pórfido sustentado por uma sereia. Entre os outros espectadores há um homem também de cabeleira avermelhada, uma cabeça de homem singular; há uma mulher alourada, toda em vestes de verde diáfano. Depois, ainda, em um fundo pleno de luz, uma multidão entre as pequenas estátuas de bronze, debaixo das lucernas

${ }^{27}$ O significado do termo ékphrasis é controverso. Enquanto Leo Spitzer (1962, p. 72) a define como uma descrição poética de um objeto pictórico ou escultórico, Jean Hagstrum (1958, p. 18) usa a palavra apenas para se referir a um procedimento poético que fala de um objeto de arte, sem voz. Mais recentemente a ligação da ékphrasis com uma obra de arte tornou-se intrínseco, não obstante o fato que só nos anos 1990 a crítica literária procurou definir o termo e a sua função com maior precisão (GOLAHNY, 1996, p. 12). Portanto, não é fácil classificá-la dentro de categorias literárias convencionais, exatamente porque faltam-lhe características formais ou sintáticas (HEFFERNAN; 1993, p. 192-194; RUBINS, 2000, p. 9). De fato, após a sua separação do contexto retórico, a ékphrasis não segue mais uma forma prédeterminada. Todavia, é sempre reconhecível por seu referente (a arte figurativa), embora possa tratar também outros temas: o artista ou a sua bravura, a reação do espectador ou, inclusive, da imaginação do poeta (GOLAHNY, 1996, p.14; RUBINS, 2000, p. 9). 


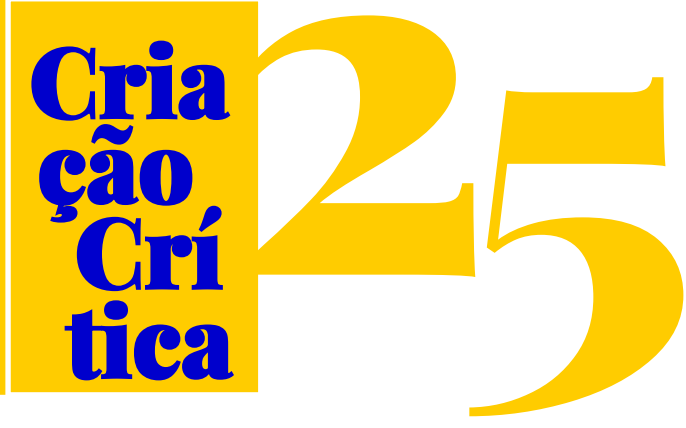

As cores se fundem em uma harmonia solene: são os azuis opacos e foscos, cheios de mistério; são os rosados femininos, cheios de volúpia; são os verdes e os violetas suaves; os negros hieráticos do mármore; os brancos metálicos dos vasos; os óxidos vívidos do bronze. Nenhuma nota ressoa; os fundos vermelhos das tábuas ex-voto são velados; as flores vermelhas sobre uma túnica amarela de uma aulete não gritam. Canta Virgílio. (D’ANNUNZIO, 1996, p. 133) 30

A terminologia utilizada por d'Annunzio para expressar gradações e nuances de cor constitui um conjunto vasto e heterogêneo, no qual desponta a importância demandada aos termos derivados (adjetivos sufixados e verbos parassintéticos) e aos referentes, preciosismos e cultismos lexicais, prediletos no plano estilístico para manter um registro elevado. Em sua maioria são adjetivos alterados que ele cria desfrutando de todos os procedimentos morfológicos oferecidos pela língua, para completar séries paradigmáticas fortemente expressivas. A preferência por sufixos que lhe permitem expressar gradações insaturadas veiculam, ao mesmo tempo, conotados sentimentais.

As qualidades apreciadas por D'Annunzio como a harmonia cromática, o aspecto marmóreo das figuras, as feições femininas de Alma Tadema - os já vistos cabelos vermelhos, mas também o vulto diáfano e a graça composta - serão ficcionalizadas em Il Piacere. Por exemplo na descrição de Dona Bianca Dolcebuono, dona de "um claro rosto oval, a testa larga alta e cândida" (D'ANNUNZIO, 2009, p. 130) 31; Dona Ippolita Albónico que ostentava uma "nobre palidez de seu rosto" (D'ANNUNZIO, 2009, p. 135) 32; Dona Maria Ferres, em cujo rosto "Uma sombra macia, tenra, semelhante à fusão de duas cores diáfanas, de um violeta e de um azul ideais, circundava os olhos dela que lembravam a íris leonina dos anjos morenos" (D'ANNUNZIO, 2009, p. 191) ${ }^{33}$; e Elena Muti cujo vulto parecia "de uma brancura quase funerária, de uma brancura gélida e um pouco lívida, que despertou em Andrea a vaga lembrança de uma cabeça vista - não sabia mais quando, não sabia mais onde - em uma galeria, em uma capela" (D'ANNUNZIO, 2009, p. 330) ${ }^{34}$.

A próxima obra descrita na crônica é uma aquarela, a mesma já apontada na crônica de Bull-Calf de 8 de março daquele mesmo ano e que servia apenas de pretexto para descrever a bela mulher que a observava. Aqui D'Annunzio fala especificamente da obra, com os olhos de um crítico:

Mas uma primavera virgiliana de arte em Tadema é o idílio da pergunta, em frente ao qual parece que certos sopros de odor marino e certas árvores cravejadas de gemas expirem sobre o rosto em um tilintar de hexâmetros de prata. É a volúpia dos ócios felizes, a volúpia da juventude. Aquela moça irresoluta, na insídia do amor, tem dentro dos olhos como que um estupor intento; parece escutar algo dentro de si, um eco do sussurro insidiante, uma vibração desconhecida que a perturba. Ela permanece perplexa, curvada na

\footnotetext{
30 "I colori si fondono in un'armonia solenne: sono li azzurri opachi e foschi, pieni di mistero; sono i rosei femminini, pieni di voluttà; sono i verdi e i violetti soavi; i neri jeratici del marmo; i bianchi metallici dei vasi; li ossidi vividi del bronzo. Nessuna nota squilla; i fondi rossi delle tavole ex-voto sono velati; le fioriture rosse su la tunica gialla di un'aulede non stridono. Canta Vergilio."

31 "un chiaro volto ovale, la fronte larga alta e candida".

32 "nobile pallidezza del suo volto".

33 "Un'ombra morbida, tenera, simile alla fusione di due tinte diafane, d'un violetto e d'un azzurro ideali, le circondava gli occhi che volgevan l'iride lionata degli angeli bruni"

34 "d'una bianchezza quasi funeraria, d'una bianchezza gelida e un po' livida, che risvegliò in Andrea il ricordo vago d'una testa veduta - non sapeva più quando, non sapeva più dove - in una galleria, in una cappella."
} 
Literatura e artes visuais: entre o lisível e o visível

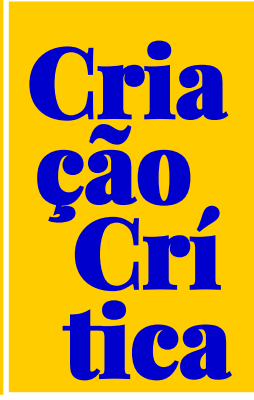

direção do jovem, como em um fascínio, com os dedos sobre os lábios, com um braço apoiada ao espaldar de mármore: sobre os joelhos as rosas perfumam, as vestes brancas fluem, e sobre aquele branco quase quente o busto amarrado com fitas de amaranto proporciona uma harmonia incerta de violeta e de leves acenos de amarelo. Ela ouve: sobre o tom fino do céu a sua cabeleira é como uma mancha de ouro vermelho. O jovem deitado de bruços sobre o banco, com o queixo apoiado a uma das mãos, dirige-lhe os olhos cheios de desejo interrogando; com a outra mão toca uma dobra de sua veste, e a ela propaga o tremor por aquela dobra. (D'ANNUNZIO, 1996, p. 133-134) ${ }^{35}$

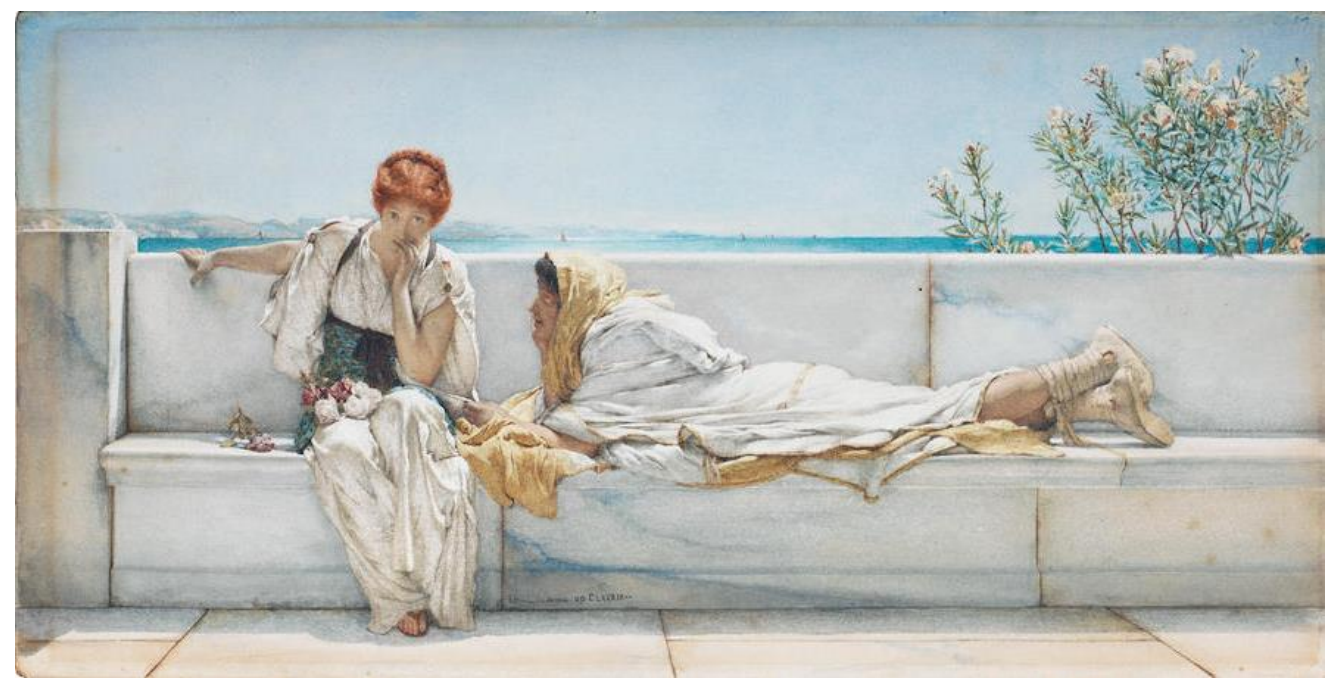

Figura 3: A question - aquarela, $23 \times 45 \mathrm{~cm}, 1877$.

Da descrição das figuras, ele passa à descrição da paisagem:

Ao redor, tudo protege. Deve ser uma lascívia tépida de ar e de eflúvios distantes; os ramos róseos do loendro áuspice surgem por detrás do mármore, florescendo ao sol; e as colinas perdem-se em fuga, e no fundo o mar verdeja, o divino mar. (D'ANNUNZIO, 1996, p. 134)

\footnotetext{
35 "Ma una primavera vergiliana d'arte nel Tadema è l'idillio della domanda, dinanzi a cui pare che certi soffi di odore marino e certi alberi gemmati spirino su la faccia in un tintinnare di esametri d'argento. È la voluttà delli ozii felici, la voluttà della giovinezza. Quella fanciulla dubbiosa, nell'insidia d'amore, ha dentro li occhi come uno stupore intento; pare come ascolti qualche cosa dentro di sè, un'eco del sussurro insidiante, un vibramento sconosciuto che la turba. Ella resta perplessa, china verso il giovine, come in un fascino, con le dita su le labbra, con un braccio poggiato alla spalliera di marmo: su le ginocchia le rose odorano, le vesti bianche fluiscono, e su quel bianco quasi caldo il busto legato con nastri d'amaranto mette un'armonia incerta di viola e di leggeri accenni gialli. Ella ascolta: su 'l tono fine del cielo la sua chioma fa come una macchia d'oro rossso. Il giovane disteso bocconi su 'l sedile, con il mento sorretto da una mano, le volge li occhi pieni di desiderio interrogando; con l'altra mano le sfiora un lembo della veste, le propaga il fremito per quel lembo."

36 "In torno, tutto protegge. Dev'essere una lascivia tepida di aria e di effluvii lontani; le rame rosee dell'oleandro auspice sorgono di dietro al marmo, fiorendo al sole; e le colline si perdono in fuga, e nel fondo verdeggia il mare, il divino mare."
} 


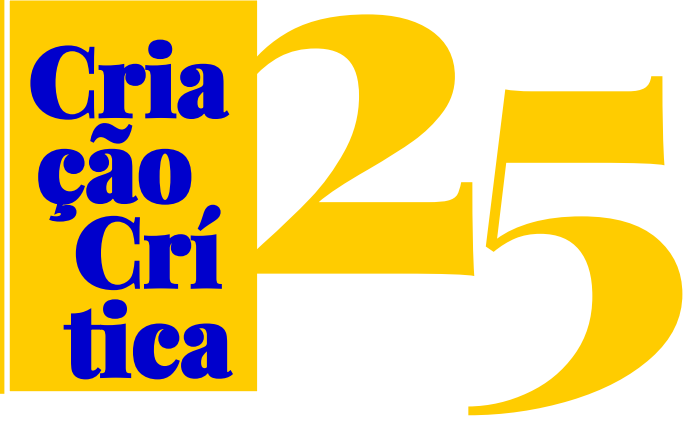

E conclui:

Esse é o idílio. Na doçura da aquarela, a rigidez gemante de Tadema se atenua; há naquele palmo de papel como que uma fusão melodiosa de cor e de execução. Fica-se em frente longamente, com um gozo brando nos olhos, com um abandono da imaginação. Pouco a pouco parece que lá, cada coisa possua uma alma, cada coisa possua uma voz: os mármores, as flores, o céu. Sente-se que sob o amor paciente daquele pincel cada parte assumiu um significado, quase que assumiu uma vida: observem uma mão, observem uma nesga de veste, observem uma comissura do banco, observem um ramo. É uma arte singular, ou seja, é uma expressão singularíssima de arte, da qual o fascínio está muito mais na cor, no caráter antigo da cor. São quase sempre meias-tintas, tons apagados, harmonizações gentis. (D'ANNUNZIO, 1996, p. 134)

A última das obras da exposição, e a menos descrita, é A Staircase (1870); a atenção do descritor recai, mais uma vez, sobre a figura feminina e sobre a escala cromática do quadro:

Olhem a Escadaria: a satisfazer-lhes os olhos, a dar-lhes uma grata sensação, basta aquela figura um pouco aguda de mulher que sobe apoiando-se ao corrimão. É uma veste cinérea, e sobre a veste um manto de um verde pálido a listras brancas, floridas de negro: uma combinação feliz, nada mais. (D'ANNUNZIO, 1996, p. 134) (38 $^{38}$

D'Annunzio, dos escritos jornalísticos ao romance, recorre a estratégias que a língua italiana lhe oferecem para cunhar cromônimos e formar um corpus particularmente amplo, rico de derivados e de compostos e, principalmente, termos referenciais, escolhidos entre os menos usuais e submetidos a frequentes processos de ressemantização e reetimologização. Para dar autoria também a termos pouco usuais, o escritor recorre ainda às fontes lexicográficas mais notáveis, em busca das denominações e, às vezes, também das citações. O léxico cromático é precioso, áulico e toma corpo através da escolha dos referentes mais raros e mais evocativos, capazes de exprimir as variações de cor.

\footnotetext{
37 "Questo l'idillio. Nella dolcezza dell'acquarello le rigidità gemmee di Tadema si sono attenuate; c'è in quel palmo di carta come una fusione melodiosa di colore e di fattura. Si resta dinanzi lungamente, con un godimento blando delli occhi, con un abbandono della fantasia. A poco a poco pare che là ogni cosa abbia un'anima, ogni cosa abbia una voce: $i$ marmi, i fiori, il cielo. Si sente che sotto l'amore paziente di quel pennello ogni parte ha preso un significato, ha preso quasi una vita: osservate una mano, osservate un lembo di veste, osservate una commessura del sedile, osservate un ramo. È un'arte singolare, ossia è una espressione singolarissima d'arte, di cui il fascino per lo più sta nel colore, nel carattere antico del colore. Sono quasi sempre mezze tinte, toni sommessi, armonizzamenti gentili."

38 "Guardate la Scala: ad appagarvi l'occhio, a darvi una sensazione grata, basta quella figura un po' acuta di donna che sale appoggiandosi al riparo. È una veste cinerea, e su la veste un manto di un verde pallido a strisce bianche fiorite di nero: un accordo felice, null'altro."
} 

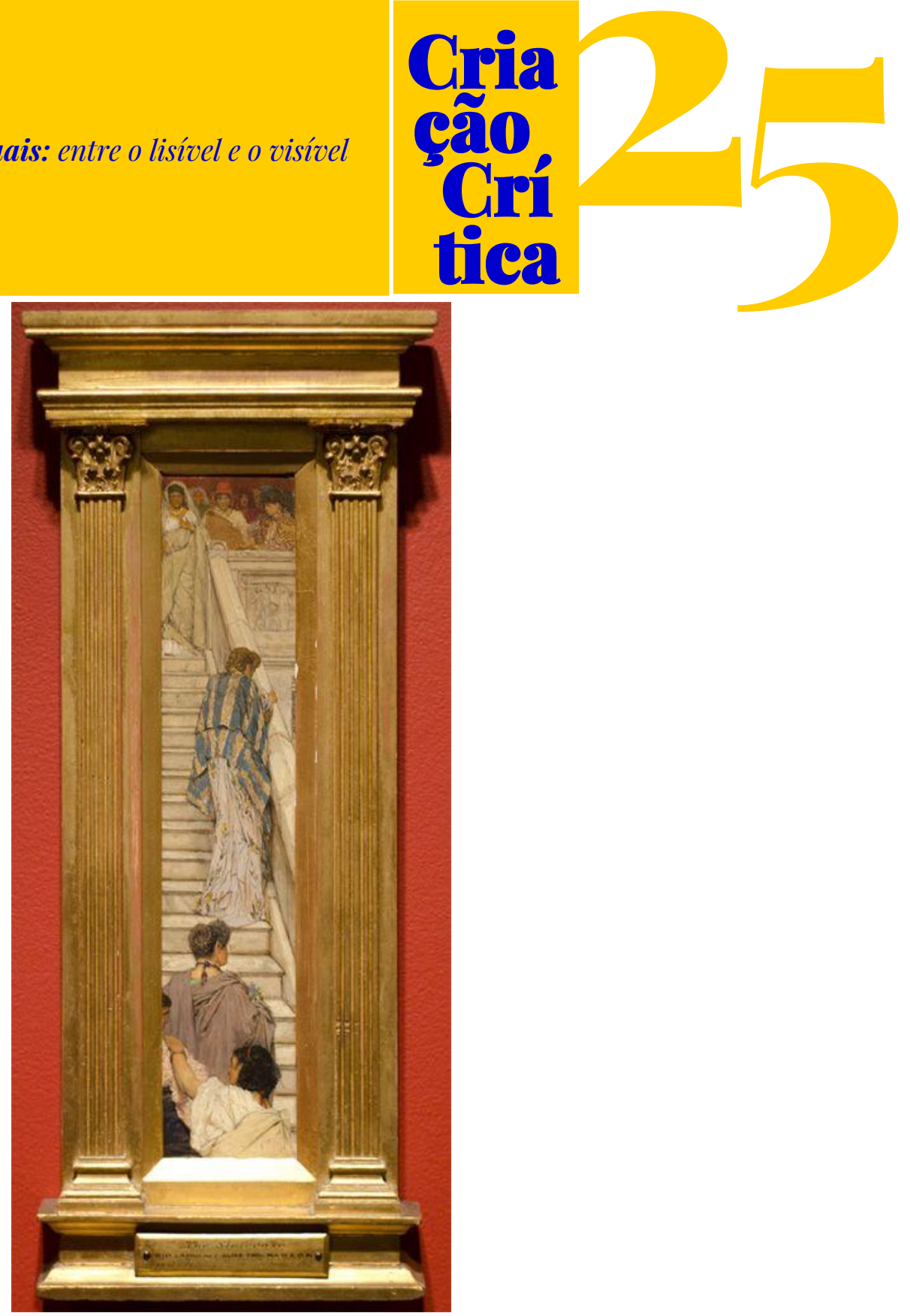

Figura 4: A Staircase - o.s.t., 42,5 X 9,5 cm, 1870.

O profundo nexo entre a pintura pré-rafaelita e o imaginário literário dannunziano bem emerge da análise do romance Il piacere que, evidenciando nele as pinturas inspiradoras, coloca em destaque como modelos poéticos as obras de Dante e dos stilnovisti do século XIII, e como modelos pictóricos os Primitivos anteriores a Rafael; na verdade, são as mesmas fontes das quais bebem os Pré-rafaelitas.

Para D'Annunzio, a ékphrasis é um instrumento apto a demonstrar a sua capacidade artística e também um meio de competir com o próprio Tadema, exatamente como se fazia na Idade Clássica em que artes figurativas e a literatura duelavam. Nas obras literárias, criativas, D'Annunzio abandona o uso repetitivo dos referentes visuais (PIERI, 2001). Os modelos tademescos demonstram que as ékphrasis tornam-se mais originais e mais livres, tendência essa bem visível nas páginas de Il Piacere. Sempre segundo Pieri,

O mundo estético de Alma-Tadema foi absorvido pela prosa de D'Annunzio. Isso é evidente em seu amor por elaboradas descrições de pintura que tentam transmitir as qualidades visuais e táteis de objetos e tecidos, e que fazem um dos elementos mais atraentes de Il Piacere. Ele optou por referências iconográficas 


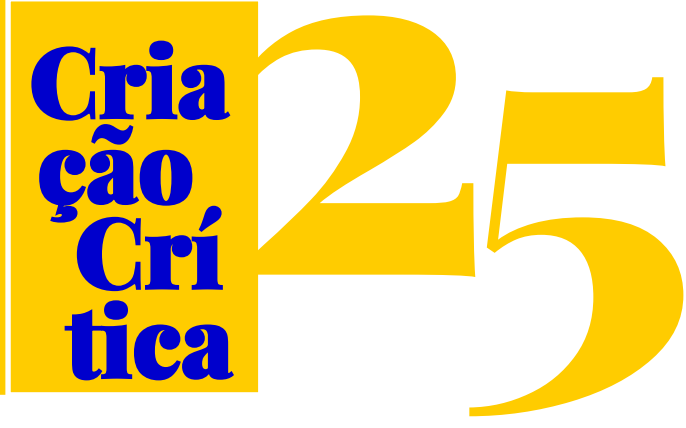

Ou em mais esse outro exemplo:

$\mathrm{O}$ banco era um semicírculo de mármore branco, limitado por todo o comprimento por um espaldar, liso, brilhante, sem outros ornamentos que uma pata de leão esculpida em cada uma das extremidades à quisa de sustentação; e lembrava aqueles antigos, sobre os quais, nas ilhas do Arquipélago e na Magna Grécia e em Pompeia, as donas ociavam e ouviam a leitura dos poetas, à sombra dos loendros, em frente ao mar. (D'ANNUNZIO, 2009 p. 216) (11 $^{41}$

O banco de mármore é muito semelhante àqueles que podem ser vistos nas telas de Tadema, principalmente em A question (figura 5) e em Saffo and Alceus (figura 5). Todavia, esse elemento não é uma invenção do artista que, provavelmente, tenha visto muitos exemplos reais em suas visitas à Itália. O loendro e as mulheres ociosas também são temas frequentes em seus quadros. Portanto, podemos falar de uma ékphrasis associativa, uma referência ao estilo ou ao topos (ROBILLARD, 1998). De certa maneira, a cena do romance recria a cena de A question: Andrea que fala e Maria que ouve, em silêncio, tornam-se protagonistas da pintura, assumindo as mesmas posturas dos personagens da tela.

D’Annunzio propõe em Il Piacere uma galeria de tipos femininos que são assimiláveis a um modelo de arte já existente desde os escritos jornalísticos. As descrições do poeta-jornalistaromancista são quase estereotipadas, e uma variação pode ser percebida, principalmente, na cor dos cabelos e dos vestidos. A harmonia cromática é, pois, uma característica relevante, e o jovem D'Annunzio deixa-se realmente impactar pela paleta de Alma Tadema, como no seguinte trecho:

Usava um vestido de uma estranha cor de ferrugem, de uma cor de açafrão desfeita, indefinível; de uma daquelas cores chamadas estéticas que se encontram nos quadros do divino Outono, naqueles dos Primitivos. [...] Uma grande fita verde-mar [...] prendia a extremidade da prodigiosa trança cadente por debaixo de um chapéu de palha coroado por uma coroa de jacintos semelhante àquela da Pandora de Alma Tadema. (D'ANNUNZIO, 2009, p. 203) ${ }^{42}$

Essa é a única clara citação de um quadro de Tadema, no romance, embora ele não estivesse presente na exposição romana de 1883.

\footnotetext{
41 "Il sedile era un semicerchio di marmo bianco, limitato per tutta la lunghezza da una spalliera, liscio, lucido, senz'altri ornamenti che una zampa di leone scolpita a ciascuna estremità in guisa di sostegno; e ricordava quelli antichi, su' quali nelle isole dell'Archipelago e nella Magna Grecia e in Pompei le donne oziavano e ascoltavano lèggere i poeti, all'ombra degli oleandri, in conspetto del mare."

42 "Portava un abito d'uno strano color di ruggine, d'un color di croco, disfatto, indefinibile; d'uno di que' colori cosiddetti estetici che si trovano ne' quadri del divino Autunno, in quelli dei Primitivi [...] Un largo nastro verdemare [...] legava l'estremità della prodigiosa treccia cadente di sotto a un cappello di paglia coronato d'una corona di giacinti simile a quella della Pandora d'Alma Tadema."
} 


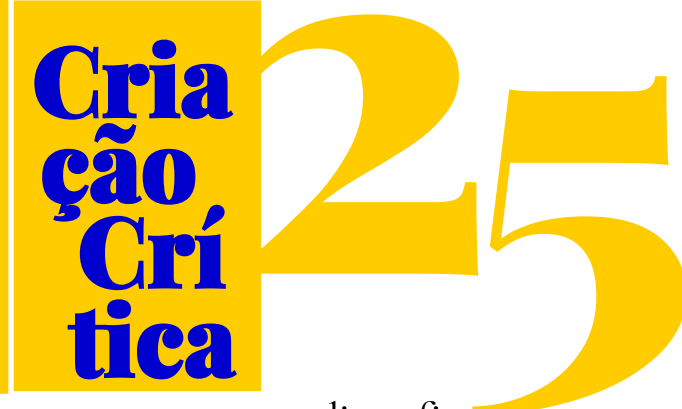

O fascínio que a arte exerce sobre D'Annunzio reside exatamente em seu polimorfismo, na sua capacidade de mesclar, como num fantástico caleidoscópio, as mais variadas sugestões, expondo-se sempre ao limite da superação da tradição e dos estilemas consolidados. Ele consegue ultrapassar as formas da ékphrasis através de um olhar visionário que investe a própria imagem operando uma recriação no próprio ato verbal de traduzir a arte em palavras. A alusão erudita das artes é revestida por uma valência metafórico-simbólica que recalca um modo interior de entender a arte como expressão autêntica da existência, como um código repleto de chamados "iniciáticos" a serem decifrados por seu poder revelador. As suas convicções estéticas, no texto de caráter ekhphrástico não podem não conferir uma nova e fascinante aura às componentes figurativas na prosa: a imagem é apreendida tanto em seu poder expressivo quanto em sua potencialidade alusiva, e a leitura se nutre de um novo ímpeto, completamente não ancorado em componentes meramente descritivas. As imagens falam à mente de um eleito, revela àquele que capta o seu aspecto mais profundo e vital do dionisíaco fogo criador. A obra dannunziana definitivamente espelha, dentre outras coisas, o gosto pré-rafaelita de ambiente europeu finissecular, atribuindo à pintura a tarefa de decifrar o texto.

\section{Referências}

ANDREOLI, A. Introduzione. In: D'ANNUNZIO, G. Scritti giornalistici 1882-1888. V. I. Milano: Arnoldo Mondadori Editore, 1996, p. XI-L.

Note. In: D’AnNUnZIO, G. Prose di Romanzi. V. I (Org. Annamaria Andreoli) Milano: Arnoldo Mondadori Editore, 1988 p. 1108-1112.

D'ANNA, R. Roma preraffaelita: note su Gabriele D'Annunzio, Diego Angeli, Giulio Aristide Sartori. Roma: Accademia dei Lincei, 1996.

D’ANNUNZIO, G. Il piacere. Firenze: Giunti Editore, 2009.

Scritti giornalistici 1882-1888. V. I. Milano: Arnoldo Mondadori Editore, 1996.

L'isotteo - La chimera. Milano: Fratelli Treves Editori, 1890.

Intermezzo di rime. Roma: Casa Editrice A. Sommaruga E Co

EBERS, G. Lorenz Alma Tadema his life and works. Trad. de Mary J. Safford. New York: William S. Gottsberger Publisher, 1886.

FORCELLA, R. "Lettere a Enrico Nencioni (1880-1896). Nuova Antologia, v. CDIII, n. XVIII. Roma: Società Autonoma "La Nuova Antologia", p. 3-30, 1939.

GIBELLINI, P. Introduzione. In: D'ANNUNZIO, G. Siamo spiriti azzurri e stelle: diario inedito (1727 agosto 1922). Firenze: Giunti, 1995, p. I-XL.

GOLAHNY, A. "Introduction: Ekpkrasis in the Interarts Discourse". In: (Org.) The eye of the Poet: Studies in reciprocity of the Visual and Literary Arts from the Renaissance to the Present. Cranbury: Associated UP, p. 11-18, 1996.

HAgSTRUM, J. H. The sister Arts: the tradition of Literary Pictorialism and English Poetry from Dryden to Gray. Chicago: The University of Chicago Press, 1958. 


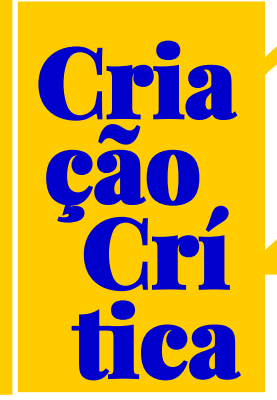

HEFFERNAN, J.A.W. Museum of Words: the poetics of Ekphrasis from Homer to Ashbery, Chicago/London: The University of Chicago Press, 1993.

HERMOSILlA, M. R. H. "D'Annunzio e Nencioni: descrizioni del personaggio femminile e ascendenza nencioniane nel "Piacere"." Studi Novecenteschi, v. 30, n. 30, p. 209-273, 1995.

PRAZ, M. Cronache letterarie anglossassoni: v. I. 2. ed. Roma: Edizioni di Storia e Letteratura, 2005.

RICORDA, R. "Benedetto Croce, Angelo Conti e "altri estetizzanti"'. Lettere Italiane, v. 47, n. 3, jul.set. p. 400-422, 1995.

ROBILLARD, V. "In Pursuit of Ekphrasis (an intertextual approach)". In: ; JONGENEEL, E. (Orgs.) Pictures into Words: theoretical and descriptive approaches to ekphrasis. Amsterdam: VU University Press, p. 53- 72, 1998.

PIANTONI, G. Aspetti dell'arte a Roma dal 1870 al 1914. Roma: De Luca Editore, 1984.

PIERI, G. D'Annunzio and Alma-Tadema: between Pre-Raphaelitism and Aestheticism. The Modern Language Review, v. 96, n. 2, abril, p. 361-369, 2001.

RUBINS, M. Crossroads of Arts, crossroads of Cultures: ecphrasis in Russian and French Poetry. New York: Palgrave, 2000.

SPEZIALI, A (Org.). Giuseppe Sommaruga (1867-1917) un protagonista del Liberty. Forli: Carta Canta, 2017.

TAVOLA, M. Dizionario dell'arte. Milano: Alpha Test, 2010.

TOSCANI, O. "La pittura all'esposizione di Roma". La rassegna italiana. Roma, ano 3, v. II, n. 2, p. $267-278,1883$. 